\title{
Foreignness and Otherness in Pedagogical Contexts
}

\author{
Wilfried Lippitz, Justus-Liebig University, Germany \\ Email: w.lippitz@web.de \\ Note: I would like to thank N. Friesen for his subtle translation.
}

The encounter with the other always means the encounter with the unknown. The unknown can be easily misperceived. As a result, the child can be systematically misunderstood, assimilated to the model of that which is known or familiar, and the unknown will consequently be reduced in terms of the grown-up or the cliché. (Langeveld, 1966, p. 31)

\section{Abstract}

This paper considers the issue of alterity in education, first defining the question of the "other" or the "foreign" as it appears in a number of educational discourses and contexts. The paper then presents two different, historically-localizable aspects of the pedagogical encounter with foreignness or otherness. Both of these are associated with periods that have an important place in German cultural and intellectual history. The first is the transition from the middle ages to the early-modern period, the time of John Amos Comenius' Orbis Sensualium Pictus. Despite the achievements of this particular work as an encyclopedic and pedagogical introduction to the "visible world," it presents a rather deleterious treatment of the foreign in its contemporaneous manifestation in Northern Europe. The second historical period is the $19^{\text {th }}$ century, and what is of principle concern here is the treatment of the foreign in grand, synthetic neo-humanistic theories of time. While the processes of dialectical assimilation and integration to which the foreign or other was subjected in these theories were not as explicit or overt as in preceding periods, they are still comparable in terms of their ultimate effect. This paper concludes by considering two $20^{\text {th }}$ century articulations of education or Bildung in which the irreducible presence of the foreign or other in human development is explicitly acknowledged and affirmed, and the issue of its respect and recuperation is directly addressed, sometimes with significant and valuable consequences for pedagogy.

Copyright 2007. The author, Wilfried Lippitz, assigns to Phenomenology \& Practice the right of first publication and educational and non-profit institutions a non-exclusive license to use this document for personal use and in courses of instruction provided that the article is used in full and this copyright statement is reproduced. Any other usage is prohibited without the express permission of the author. 


\section{Introduction}

The word "foreign" ${ }^{1}$ is not easily defined in completely decisive and positive terms. That which is foreign does not belong to any set of binary oppositions, such as friend or enemy, self or other, in or out, subject or object, me or you, bad or good. If one uses a phenomenology of the lifeworld to ask not what the foreign is, but rather, how it appears and reveals itself, then an initial definition emerges: "Foreign " is a relational concept, referring to phenomena that always appear and achieve articulation in relationship to something that is not seen as foreign. That which is foreign is thematized through our systematization and ordering of the world, in all of its dimensions: ${ }^{2}$

1. In the axiological, concerning values: between good and evil, same and different, familiar and unfamiliar, beautiful and ugly, etc.;

2. In the praxeological, concerning praxis: between convergence and divergence, integration and differentiation, super- and sub-ordination, acceptance and rejection, etc.;

3. In the epistemological, concerning knowledge and perception; between knowledge and ignorance, familiar and unfamiliar.

Described in relational terms, it is clear that "foreignness" is something that, to various degrees, doesn't fit into available structures, and that even tears through the warp and woof of the textures of the everyday. In doing so, it leaves behind fibers, fragments or traces of the contingent and arbitrary. Every human order is built on continuity, regularity and dependability. ${ }^{3}$ These orders constitute themselves -insofar as they are able to secure and maintain their own identity - in processes of the inclusion that which belongs to it, and of the exclusion of that which is other, that which is foreign or abnormal. In the radical sense of an anarchic element or event, the "foreign" cannot be integrated into such an order. For it is part of the realm of the unordered, of the unrestrained and unbridled. It eludes every effort and exertion of force that order might bring against it. Instead, the foreign remains something which continues to irritate, which disrupts or interrupts, and destabilizes the given order. It is evident from such disruptions that any achievement of order remains precarious. Order has its origin in the pre-predicated and pre-reflexive -an origin which cannot be comprehended in terms of order's own norms and rules. That which underlies order in other words, is also largely invisible and unstable, and ensures that the order itself does not become ossified. Orders remain in this way dynamic and unconfinable systems. They can be compared to languages. They are not preserved in fixed vocabularies and grammars, but remain alive and develop further in creative processes of concrete speech and in contexts of symbolic and pre-symbolic activity that cannot be planned in advance.

If we understand education and our own pedagogical reality as an active and reflective practice which arises, and is changed and maintained in systems of order, then education -like other social fields - is thoroughly interpenetrated by foreignness. As an example, schools have continuously been given the task, as organizations, of dealing with the problem posed by in every society, that of its social reproduction. This consists of the integration of new generations 
into the existing society through exclusionary and homogenizing practices and processes. For the social system of the school, its entering students, its newly arrived clients, are in a certain sense foreign. A flood of literature --scholarly and popular, practice-oriented and autobiographical-deals with the first day of school, with the transition to school, and with the performance of rituals dealing with the "newness" and "otherness" that these phenomena present. The attempt is to deploy specific aspects of practice and of normalization, to make students out of children who have only known the family or the kindergarten, and to curb the "pathologies" or irregularities that readily accompany such assimilative processes (Lippitz \& Levering, 2002).

Of course, when they begin school, new experiences lead children to feel alienated and insecure. They enter into a new place, one that follows patterns different from those that the children are used to. Punctuality is required, and is almost physiognomically embodied in the austere face of the clock in the classroom, which inexorably and admonishingly indicates to latecomers the breach of academic order that their lateness represents. One meets the functionality and the impersonality of the institution in the monotony of the architecture of the school and the classroom. Also, there are manifold duties and assignments -- whether one likes them or not -- that are all subject to official inspection and evaluation. Breaches of rules and irregularities are seen in such institutional orders as bringing with them clearly specified consequences. Last but not least, it is in the school that strange grown-ups appear, in loco parentis: Teachers, principals, counselors and others, each with their own claim upon the child (Langeveld, 1966).

Out of this multiplicity of manifestations of the foreign in its "normalcy" and "everydayness," I would like to select a few, more or less dramatic aspects of foreignness for further consideration. Although they may be novel and foreign to English readers, I believe these aspects to be interesting in their own right, and they show foreignness as a central and timely problem for pedagogical thought and action. I will articulate the significance of foreignness with reference to the dimensions presented above:

1. Epistemologically and praxeologically in terms of the question of personal formation, socialization and development;

2. Epistemologically, axiologically, and praxeologically in terms of ongoing discussions about pedagogical understanding and about basic conceptions of pedagogical practice;

3. Intergenerationally, in terms of the formation of the interrelationships between age groups central to social reproduction.

\section{Between Cosmological Bildung (Amos Comenius) and Neo-Humanistic, Self-Bildung (Wilhelm von Humboldt)}

In the following, I will present two different, historically-localizable aspects of the pedagogical encounter with foreignness as this concept has been described above. Both are associated with periods that have important places in German cultural and intellectual history. One of these periods is from the transition between the middle ages and the early-modern period, and the 
second, from the $19^{\text {th }}$ century. Indispensable to both is the German conception of Bildung, a term central to German-language discussions of pedagogy, but with no direct equivalent in the English language. Some have characterized it as designating "the character-forming surplus beyond mere knowledge and skills that is at the centre" (Künzli, as quoted in Westbury, 1999) of German understandings of pedagogy. Speaking in more positive terms, its meaning may most readily find illustration in the word Bildungsroman. This imported literary term refers to the novel of education or formation --of which Adventures of Huckleberry Finn or To Kill a Mockingbird are prominent English-language examples. As the themes and developments in each of these novels suggests, Bildung is both an informal, social and a institutional, individual process, involving personal formation, socialization and development in the broadest senses of these terms. Bildung thus designates a comprehensive process through which one becomes both an individual (on the one hand), and also a part of a society and culture (on the other): In other words, it designates the attainment of "reasonable self-determination, which presupposes and includes emancipation from determination by others" (Klafki, 2000, p. 87).

The first aspect of the pedagogical encounter with foreignness to be considered here has to do with the material, epistemological and axiological side of Bildung. It finds its specific historical location in what is likely the greatest attempt by any scholar to establish a pedagogically significant order of the known world. This is undertaken by John Amos Comenius in his Orbis Sensualium Pictus (1658; also titled Die sichtbare Welt/The Visible World). The other aspect has to do with the rather theoretical side of the process of Bildung as it is conceptualized in the neo-humanism of Wilhelm von Humboldt. Specifically, this is Bildung as a movement or dynamic, as a self-directed, enriching experience occurring as the self encounters and assimilates the other and the foreign or strange as these are presented by other languages and cultures. Given their importance in German thought, both of these historical understandings -the medieval-humanistic and neo-humanistic- have important practical and cultural implications. For example, Comenius' cosmological view of the world can be said to lead to a canonization of the material form of Bildung, which connects the social utility of skill and knowledge with the moral disposition that is bound up with it. The formal, neo-humanistic concept of Bildung, of the dynamic development of the abilities of the individual, appropriates the foreign or other of an idealized, past culture for the purposes of higher education. Bildung in this sense then becomes an end in itself, a general process of formation without the utility of an ultimate occupational justification. These differentiations are clarified in greater detail, below.

But what does Comenius' Orbis Sensualium Pictus (1658/1910) ${ }^{4}$ have to do with foreignness? It arose as an attempt, on the universal and cosmological scale, to create some order from the political and social chaos of the Thirty Years' War (1618 to 1648). The divine order, of whose existence Comenius is still convinced, is understood to be hidden by the confusion of war and religious strife. The world is no longer the familiar home it once was; it has become strange and foreign. God's order, on the other hand, is hidden, and it must be artfully re-created in trust and belief in the presence of the Holy Spirit; and it must be imparted to all people through an ambitious and systematic effort of Bildung. The invisible order of the world is made visible and accessible through reading and learning, through the careful and methodological arrangement of word and picture -and the juxtaposition of the common German with the elevated Latin language. All of these linguistic and imagistic forms and contents are combined to achieve a 
Christian legitimation of the world in its totality. Through the careful combination of text and image, "foreignness" is made accessible for learning, in the broadest possible manner. This includes the literalization of forms and contents in word and picture; it also includes separate or even isolated places of learning and systematic instruction. Such an intensely mediated and didactic presentation of the world attains the status of a true and divinely sanctioned "reality," ontologically primary to chaotic, everyday realities, elevated above the merely factual and empirical world of the senses and of action. To exaggerate slightly from our (post-)modern standpoint: The simulacrum is more real than the real itself, and presents a didactically artful, cosmologically-scaled artificial world to the student, who inhabits a world rife with the familiar and unordered. And at the center of this is the artificial world of the school! What pedagogue would not be inspired by such a cosmology, and its assignment to the school and to educational efforts of this position and power? The metaphysical principle of a progressive order or hierarchy leading from physical and visible up to the invisible heavenly realm of ideas is typically Christian and medieval and even Greek in origin. The invisible, intangible and divine is the exclusive purview of the soul, of that which is eternal in human beings. It alone exemplifies the rational order of the whole, and the more disorderly, earthly world of the human must be brought in line with it. According to this way of conceptualizing order, "foreignness" is only transitional, and a type of "sickness" or "sinfulness" that can always be healed in the great beyond. "Foreignness" has no value in and of itself in the sense of the modern understanding described earlier, in which "foreignness" can at least provide a basis out of which order is generated.

Earlier, I indicated that orders are created through the selective processes of inclusion and exclusion. These "orders" suppress disorder in particular ways, in that they privilege some things in particular, and at the same time, through processes of exclusion, segregate that which is considered different, foreign, or of less value or simply incapable of integration. One short note can serve at once to illustrate Comenius' approach, and to point out a further set of issues.

I would like to comment on one specific example of an attempt to create order that is evident in Comenius' work. It concerns a central site of the civilizing process of the modern individual. This civilizing process is, and remains today, one of the tasks of the education, a central part of raising a child. This is the cultivation of an individual's table manners, a type of cultivation, education or discipline, which places significant emphasis on the body. As Norbert Elias (2000) has shown in his studies of the history of the civilizing processes of modernity, this process or program involves the cultivation of those less civilized -or even "barbaric"- by adjusting the threshold of embarrassment and shame (p. 72). Certain bodily functions and associated organs are made foreign and strange. They are expunged, rendered taboo both in speech and action. They are silenced, often withdrawn from that which is part of the desired, moral and cultural order, and from that which is seen to constitute the "humanity" of human beings. This is also the case for the way that food is handled at meal-time. A treatment of this particular subject is provided in Comenius' Orbis sensualium pictus (1658). A facsimile of the image and text used by Comenius is provided here (see overleaf), and is typical of his treatment of dozens of other subjects -from water to warfare- undertaken in this landmark work.

Cleanliness and order is maintained through a range of instruments and arrangements, from processes of hand-washing, through the pouring of beverages from pitcher to glass, to the roles of guests and host. But to return to Elias, it is above all cutlery, listed near the top of 
Comenius' vocabulary (Löffeln, Messer, Gabeln; Cochlearia, Cultros, Fuscinulis), that keeps a distance between food and the body. At the same time, these instruments --indispensable to civilized culinary conviviality-- touch one of the most intimate parts of our body, namely the mouth. Other intimate places and organs, specifically, those for elimination and reproduction, are correspondingly rendered foreign and taboo. These taboos are rearticulated surreptitiously as repressed libido in the pathologies and neuroses of later generations of puritanical and Victorian bourgeoisie.

But that is another topic that cannot be considered further here. What is important at this point, however, is that in the Orbis, in which Comenius generalizes the manners and customs of the higher medieval classes to the terms of a universal benchmark for Bildung. These manners and customs are to reach the lower classes and social groups in the course of modern processes of civilizing and social-discipline. In Comenius' richly illustrated text, the everyday lives of those not a part of the privileged classes is effectively rendered invisible. According to Comenius, Bildung applies to everyone, including those less privileged. As a result, the issue of foreignness is tacitly raised and at the same time, also expunged in Comenius' conception of Bildung. And this selective inclusion of order and exclusion of foreignness occurs along lines of social class. Less privileged elements have no place in the order of the whole as it is presented and integrated into a divine and all-encompassing cosmology.

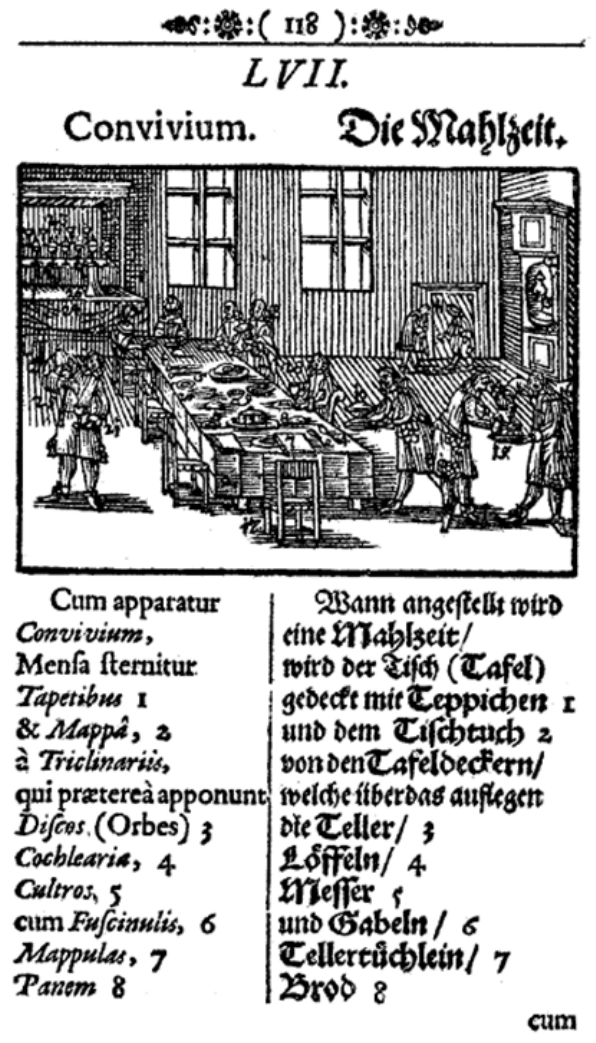

\begin{tabular}{|c|c|}
\hline 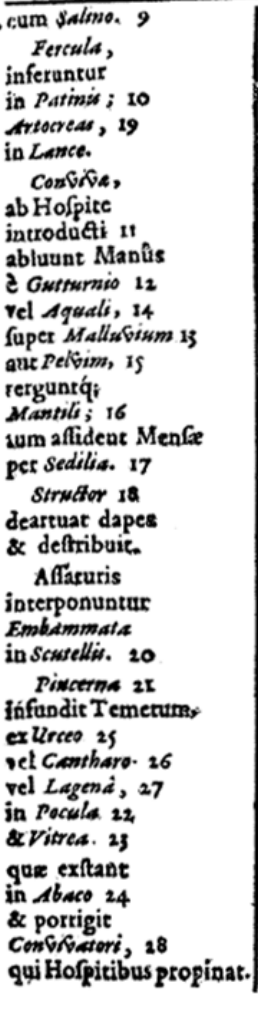 & 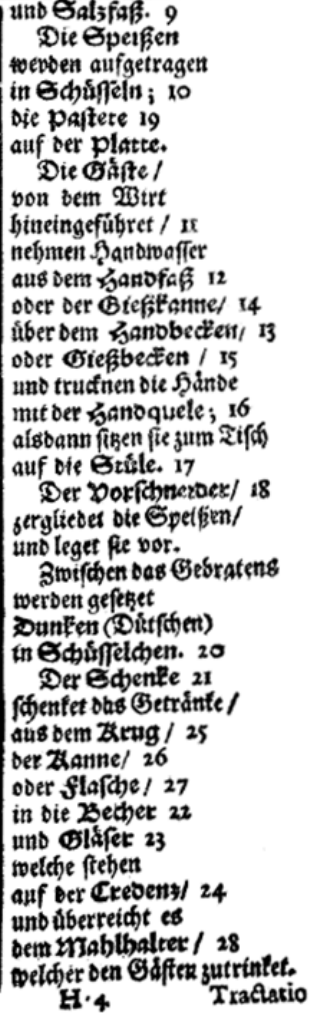 \\
\hline
\end{tabular}

Figure 1: Convivium, Mahlzeit (Mealtime) from Comenius' Orbis Sensualium Pictus 
Creating order out of chaos is an unavoidably imperial gesture. In making one thing privileged and familiar, order unavoidably makes another "foreign." This is basic to everyday experiences of Bildung as it occurs in the supposedly central or paradigmatic order of the school -something which Comenius anticipates in its basic structures and implications. Comenius' optimism regarding Bildung, however, does not hold in our present age. The order which he elevates and universalizes is now generally denigrated as particular and exclusive. Since the school has become one of the central authorities for socialization and teaching, it has to deal systematically with problems of the selection and justification of appropriate content for learning. Like Comenius, the school must attempt to present the world in literalized form in its textbooks, and to give it canonical order in its curricula. In this way, it accordingly excludes from its institutional logic and its inherently middle-class orientation other social and individual characteristics. These become, in effect, foreign objects in the school, since they apply to the role of neither student nor teacher. It is precisely this that has resulted in the "foreign" or alien nature of learning in school, in the many baleful experiences to which generations of students have given expression. The order of the school and classroom is experienced as senseless filler and alienated learning. As a student in school, the child, in his or her person, is split: On the one hand, there is the individual in the plenitude of the child's biographical experiences and adventures, which remains foreign to the teacher; on the other, there is the child in his or her role as a student, a role which is a foreign imposition, ultimately remaining external to the child. However, it goes without saying that the creation of maintenance of this order -and of the foreignness and alienation associated with it- is undertaken in the school with ever less success and conviction. And the remedial impulse in pedagogical-reform movements makes this its explicit program: To bring into the school the extra-scholastic reality, the biographical and experiential dimensions of learning, the transparency and even the somatic and sensual proximity of learning contents so that education may be more relevant to life's meaning (Schiebe, 1969). ${ }^{5}$

Let us now turn to the neo-humanistic discussions of Bildung. In these discussions, too, there is talk of foreignness and alienation. Foreignness appears, however, only as something preliminary and temporary. In its ideal form, Bildung is understood in this context as selfBildung, as an experiential process that arises through negative occurrences and alienation. The subject of Bildung in this context is understood in terms of identity theory. Starting with the individual subject, Bildung in the broadest sense is the reconciliation of the individual and the particular with the general and the universal. Experience is dialectical in nature, and is ultimately consummated only through a long and arduous confrontation with and assimilation of the other. Bildung happens through learning, unlearning and relearning; it is occasioned through negative but formative experiences. Through such experiences, I alienate myself, in that I deal with things unfamiliar and unknown --for example, a foreign culture or language-- which demands significant effort and assimilative labor.

This general process has one of its most dramatic formulations in the Hegelian dialectic or struggle between master and slave for recognition, in which self and other are pitted in a contest, literally to the death, for autonomy. In the end, this struggle results in the appropriation of that which is other and foreign by the victorious self. If it succeeds in its self-assertion, the self then subjugates the other and in this way renders it familiar, and eliminates its foreignness. In this struggle of the self against the other for autonomy and recognition, the self is of course 
changed, and becomes something different. It is strengthened and enriched, and it is able to enjoy new experiences at a higher level of consciousness. In other words, the self integrates the foreign and other, and in doing so, comes to know itself better, becoming in a sense transparent to itself. The path of Bildung starts in imperfection and in a dearth of self-consciousness. But it ultimately leads to consummate self-knowledge and self-awareness in the form of what Hegel has called "objective spirit."

In keeping with the traditional modern metaphysics of the subject, the self in this scenario establishes its own identity through the reflexive encounter with and adaptation of the other. This dialectical experience enriches the self by providing it with the distance necessary for it to come to know itself better, and to be better taught about itself. ${ }^{6}$ That which is other and foreign becomes simply a means of Bildung, and carries no other purpose in itself. When the other or foreign becomes knowledge, it is always presupposed that this otherness or foreignness is not fundamentally different in comparison to the consciousness which experiences and reflexively appropriates it. It ceases to be something that is known even its foreignness, and becomes a part of reflexive consciousness. The initial difference between the self and other, the starting point of the self and the knowledge of the other, is effectively erased. It disappears in the sameness of reflection. The other and the foreign are figures of passage, not insuperable barriers to thought and understanding.

Theodor Litt, a philosopher of education well known in Germany, provides an example of how this abstract model of Bildung is concretized (e.g. Litt, 1965). Explicitly situating his thinking in the type of philosophy of identity described above, Litt makes the following argument: The general Bildung of adolescents should include, Litt says, a foreign language. In this way, Litt explains, the adolescent will be removed from the familiar and unreflective speech of his mother tongue, and will gain distance from it. Only in that way, can the adolescent achieve two new experiences that are closely interrelated: First, he or she will learn a new language, and with it, a new culture and way of life; second, this learning process will provide a mirror, in which the old and familiar, the trusted, appears changed. The first language or mother tongue is made reflexive; it is made to appear as something special, with its own grammatical, semantic and syntactical idiosyncrasies. Accordingly, learning a foreign language means simultaneously to learn something about that and to also learn much about one's own. However, Litt goes even further, and in doing so, follows the integrative, totalizing dynamic of the Hegelian dialectic of mentioned above. Learning a second language, Litt argues, can be tantamount to overcoming its foreignness: Through learning and reflection, as Litt would have it, one can come to "know" a second language with the intimacy and familiarity with which one knows one's mother tongue. Learning a second language, Litt continues, not only illuminates both languages, but can also shed light on the "objective spirit" of language "in itself" --as a manifestation of that objective spirit which is transcendent of the individual and his time: The "objective spirit" of language becomes "wed" to the individual subject of Bildung and to his mother tongue in such a way that that "the general" is truly manifest in the particular and the individual. This bold construction of the philosophy of identity guarantees that in the final end, the self, as well as the other and foreign, are made structurally identical.

In these neo-humanistic accounts, foreignness thus appears only as a transitional, temporary phenomenon. Universality and generality has logical precedence over individuality 
and particularity. If one translates this model of language learning as a whole to the process of Bildung, then one can say the following: Bildung in its essence succeeds when one's own goal and that which is foreign are conjoined to a common purpose. And this purpose is itself the fundament of the subjective and the individual. With this guarantee of identity, Bildung, however, loses its individual and processual character. This character consists in the fact that new experiences of the foreign do not complete themselves in some form of finalized, general knowledge. Whoever looks at intercultural learning and communications processes, for example in their historical manifestation in the European colonization of the "foreign" world since the $15^{\text {th }}$ and $16^{\text {th }}$ centuries, will be shocked at their violence and destructive power. In the name of the socalled universalism of European cultural and religious understandings, that which is other and foreign was violently "appropriated" and "understood," nearly to the point of obliteration. This occurred with the help of ever more refined methods of understanding the foreign, and of translating the languages of so-called primitives into European language-systems under -all under the aegis of power-political and strategic goals. In this historical context, knowledge of the foreign became-as Foucault has shown in his genealogical studies-a question of sheer authority and power, in which identity is created through the forceful reduction and levelling of everything that is different and heterogeneous (e.g., see Todorov, 1999).

But it is also possible to look at Bildung generally from a different perspective -one that emphasizes the limits of knowledge integrating and reducing the others to the terms of the self. In this sense, Bildung is not so much a process of "becoming oneself" as it is one of becoming foreign and other, through the encounter with the other. Bildung in this sense is not a process of centering consciousness, but of de-centering it. It is only when students experience the inevitable limits of knowledge of the foreign and other that these same students are able to remain truly open and curious. In this sense, the experience of coming to terms with a foreign language and culture is marked by the awareness that one cannot simply appropriate it as a whole, and that one cannot become familiar with it in the same way that one is familiar with one's own mother tongue and autochthonic culture. Among other things, such an awareness is necessitated by the pre-reflexive and pre-predicative roots in which the student has been born and raised, before he or she can even identify "language" as an explicit theme. Paradoxically formulated, children can speak before they are conscious of language itself. If later, through conscious processes, children do learn a foreign language, they are then confronted, through means both methodological and didactic in nature, with a linguistic system which remains in a certain sense "artificial," and in no way shares the self-evidence and fluid expressivity of one's own mother tongue. In learning a new language, the learner is also in a certain way also dispossessed of it.

This is not unusual, and applies to many processes of learning and Bildung in complex societies. One can see this in all its intricacy and systematic interconnection, not directly through the senses, but in a theoretically abstract, didactic and methodological knowledge. Such knowledge is not simply a reflection of reality. It is something else, since it can be "knowledge" only in an "artificial way" -a knowledge which refers to a reality which itself cannot be wholly absorbed into knowledge. Remaining outside of and in many ways alienated from this reality, knowledge in this modern and post-Hegelian sense is principally perspectival. This means that other knowledge is always a possibility, but not a matter of necessity. Such knowledge is an integral part of the historical-contingent mode of experience in critical modernity. Knowledge in 
this sense is always "critical" knowledge, a knowledge of differences, indexed according to degrees of otherness, foreignness and uncertainty.

\section{The Problem of Pedagogical Understanding of the Other and the Foreign}

Thus far, this brief, recuperative recasting of Bildung has made it clear that experiences associated with it cannot complete themselves. They necessarily come up against internal limits, in the form of the foreign and then other that cannot be integrated. To consider this further, I now turn to the pedagogical understanding of the child and adolescent. The citation from Langeveld provided at the outset of this paper provides us with an important point of entry to such an understanding. Adults, as Langeveld describes, see children in a manner that is only abstract or schematic. Professional pedagogues especially are subject to this kind of danger, since they work with a multiplicity of models and theories, for example, with psychological models of development, or with concepts of socialization and sociology generally (Gstettner, 1979). The results of such schematization and systematization are not necessarily immediately obvious. These systems operate in a realm of the general beyond the individuality of the child, and they often reveal a deterministic picture of human kind, in which one finds little room for childhood creativity, inventiveness and spontaneity. The child then is and remains that which is foreign, that which is other and which is not "thematized" in analytical terms. In this sense, as an object of theoretical-reflexive thought, the child eludes the practice of identification and therefore also of ready theoretical access. Experienced practitioners and theoreticians observe the absence of such means of access, and lament the misunderstandings that result. But how could such access be gained?

Humanistic pedagogies in Germany readily make one aware of the limits of pedagogical understanding and action. These pedagogies and theories extend well beyond the "proto"humanism of Comenius and the neo-humanism of von Humboldt. They are strongly influenced, for example, by understandings of ethics and individuality articulated by Kant, the hermeneutics of Schleiermacher and Gadamer, and include approaches ranging from second-wave cybernetics to phenomenology. The limits of pedagogical understanding and action are articulated in many of theories and approaches using different arguments and models of understanding, and these betray different degrees of radicalism. Here are two examples, with brief discussions of how each sheds different light on the child as other or foreign:

- Theories of pedagogy and of the subject in the Kantian transcendental philosophical tradition emphasize the indissoluble pedagogical antimony between education and freedom. These theories are based on the model of the individual as a citizen of two worlds (1929). ${ }^{7}$ On the one hand, the individual is an animalistic being, driven by need. Child and adult alike are slaves to causal-deterministic processes, such as feelings, motivations, interests, and requirements. The business of education is to counteract, control and tame these animal limitations through discipline, breeding and cultivation. On the 
other hand, humans are also intelligent and free beings, and thus capable of practical and reasonable self-determination. Of logical necessity, this reasonableness, and the ethical autonomy associated with it are both absolute and $a$ priori. This means that these characteristics actually cannot be effected through education, which always is to some extent an exercise in coercion, and therefore a form of determination-through-others (rather than determination through one's self). Pedagogical thought and action in the Kantian tradition is intrinsically paradoxical: It applies to a moral subject, which at the same time is necessarily not subject to such pedagogical treatment. Whoever begins an education, loses his freedom as a subject in order to gain it. From the viewpoint of those engaged in pedagogical activity, such activity is limited to exercising its influence over human nature over the realm of human wants and needs. Understood as a means of becoming human, pedagogy is necessarily deterministic and quasi-technological. But this is precisely what pedagogy does not want to be. To again invoke Hegel, the pedagogue can be said to suffer from an unhappy consciousness: she wants to act, even though such activity is impossible. She wants to reach a goal, which by its very definition must elude her.

- Humanistic approaches to pedagogy, in conjunction with traditional Christian conceptions of metaphysics and of the individual, together provide a different avenue for pedagogical theory and action to take place (Meyer-Drawe, 1999). This is indicated in the notion of the individual as having been created in God's likeness, with the corollary that the ethical and moral relationship between God and the individual cannot be influenced by anyone else. Not only is this relationship exempt from external influence, but in some senses, it is beyond even the internal influence of the individual him or herself. For "Bildung" in this sense is a "gift" from God, an act of grace on the part of humanity's divine "other." From the perspective of the development of personal morality and conscience, this gift is a particular kind of external determination, which "calls" the self in its true selfhood. We still say we are "called" to a profession or role, as if our development toward it were ordained by some higher power. What emerges from this line of thought is a model of Bildung that is, in effect, dis-integrative: Being and becoming one's self is, in the depths of the person, a process of becoming other. The Judeo-Christian edict against idols or graven images underscores this: The "becoming other" of the person, whose soul has been created in the image of God, cannot itself be presented imagistically. The pre-figuration, the goal of human development must not be specified. The movement of human Bildung thus remains a search without a final known goal. In the sense of a simple unambiguous determination, pedagogy never reaches its goal. The last and authentic goal of pedagogy, of the work of Bildung, is the self-determination and self-becoming of the individual -a goal that remains a sacred secret. As such, this final purpose ultimately remains at a distance from the efforts of the most earnest 
pedagogue. Again, this leads to a paradox: Pedagogy is most effective precisely when it has least effect.

Is Bildung and education therefore ultimately and unavoidably limited to just what the individual, him- or herself can achieve? Is Bildung necessarily limited to self-Bildung and selfeducation? Even further, is education robbed of its goal-oriented, instrumental or even technological character -so readily expressed through terms like "objectives" and "outcomes." Foreignness, as articulated by the likes of Langeveld could not confirm such conclusions more forcefully. It finds further confirmation in the general humanistic pedagogical tradition. Like the Judeo-Christian interdiction against graven images this tradition does not subscribe to an objective ideal of Bildung or concept of culture. As a result, it does not seek to act directly upon the student in a direct, causal sense -unlike, for example, empirical-scientific theories of education. In this pedagogical tradition, the teacher or adult generally serves as an example, the representative of the dominant culture for the child. But this exemplification and representation works through an appeal to morality, rather than through practical manipulation. Furthermore, this tradition underscores that the child is a being who, in the future, will be self-determining. Consequently, the child undergoing Bildung should take learning, and those tasks associated with it, into his or her own hands. A non-empirical, axiological model of the Kantian duty to one's self takes the place in this pedagogical tradition, of the place of a causal model of pedagogical effects. This duty to one's self can be introduced through "diluted" empirical models of cause and effect (such as pre-personal processes of habituation) or even through coercion. Either path can be taken to address the aforementioned Kantian paradox in the humanistic pedagogy between freedom and necessity. Whatever way related pedagogical understandings are refined empirically, and expectations for education are coordinated using ever increasing developmental understandings of moral, cognitive and social competencies, at least in the development of leading models of pedagogical understanding, the difference between children and adults remains. ${ }^{8}$ In the context of this pedagogical orientation, this set of concerns is often expressed in the notion that education requires a balance of risk and trust (Bollnow, 1984). Risk and trust need to be balanced by the educator, who does not know what the child will ultimately make of his or her pedagogical efforts. Risk and trust refer to the uncertainty and danger inherent in the business of education. These are not contingent, but necessary modes of educational action and behaviour. Since the autobiographical processes of Bildung does not admit of direct causal relations, the pedagogue must risk action that will have unknown effects, and must trust that its effects are ultimately salutary.

Such humanistic-pedagogical understandings end up emphasizing the difference between the generations. But in the final end such a humanistically-oriented pedagogy lives out of an optimistic view of the relationship between the generations. Foreignness is an important theme in this pedagogy, of which Langeveld is a prominent proponent. But foreignness does not experience any dramatic amplification when the goal of education is taken to be the integration of the young into the continuities and traditions of adult generations. The aforementioned optimism emphasizes the resolution of any difference and foreignness that might separate the generations, assuming that this is overcome through the integrative work performed on or by the young. ${ }^{9}$ 
Foreignness is given more dramatic expression in other variations of German pedagogy. It is an important factor not only in the process of building understanding between generations, it is often a virulent driving force in an individual's life-history. It is a part of one's relationship to oneself. The individual encounters himself as a foreigner; everyone is in important aspects of his or her existence an unknown being. Siegfried Bernfeld (1925), one of the first German psychoanalysts and Marxist educational theorists to gain prominence after the First World War, provides a powerful description of how intergenerational foreignness emerges in the relationship between educator and child: Regardless of their professionalized status, the roles of the educator and teacher have something to do with a peculiar professional deformation, with an unavoidable incompetence. When encountering any one child, the educator actually has a mostly unnoticed and little considered relationship with two children: with the concrete child before her, and with the recollection of the child she once was -the repressed and damaged "inner child," so to speak. Of course, Bernfeld developed this diagnosis in the context of the family-induced, repressive and neurotic suffering of the child in the authoritarian-bourgeois patriarchal society of the turn of the century. Such a society was thoroughly repressive. The psychological dynamic with which it is associated is at once powerfully effective, yet ultimately inaccessible to rationality. It renders impotent all moral and professional-ethical attempts to engender respect for the individuality of the child -or it makes such attempts appear only as ideological euphemisms in what is actually a coercive relationship. The concrete interaction between the educator and the child leads the educator, against her will, to undertake some form of revenge or compensation, for that which she, as a child, had suffered at the hands of her parents and then repressed. A psychological projection of the child inserts itself in front of the concrete child, as he or she is encountered by the teacher or educator. This image is, in a sense, foreign in different ways to both child and teacher. The pedagogue actually has nothing to do with the concrete child; the child as such remains foreign to the pedagogue. At the same time, the child also remains foreign to the unenlightened pedagogue, when he or she acts impulsively or unconsciously. A pedagogy of good intentions and good will is, in this sense, is made suspect and fundamentally delegitimated. Anti-authoritarian and anti-pedagogical thought find in such a psychoanalytic construct of foreignness their subversive well-spring. But regardless of how they are phrased, there still are no answers to a number of questions that follow: How much are normalizing or idealizing constructions of psychoanalysis themselves to blame for the desultory projections and compulsions of the pedagogical act? And how does psychoanalysis exempt not only pedagogy, but itself from this fatal involvement with childhood, which is so important in its diagnosis of pedagogy? And does such a diagnosis of compulsive foreignness of the educator not also mean that "foreignness" itself is only due to insufficient psychoanalytic knowledge, and therefore it can also be fundamentally reversed?

\section{Limits of Pedagogical Understanding - the Child as Foreigner}

By way of a conclusion, it is worth looking at a much more radical pedagogical version of foreignness. It also has to do with the generative relationship between adult and child invoked by 
Langeveld. This is given rich expression in this literary description written by someone in the process of becoming a father:

These eyes should never be your measure, and when you experience me through such a judging glance, then I beg you ...to forget me. You should penetrate behind such eyes, which are fixed on the past, which would reduce your being as a child to a mere developmental phase, to a mere preparatory moment in order to achieve a more comprehensive view of the world... (Kolleritsch, 1986, p.79)

Here, a father effectively radicalizes the statement of Langeveld cited above. He promises not to assimilate his child to what is systematized, known, familiar or clichéd. In a sense, the father imposes upon himself the biblical command against graven images, which lies at the heart of the Jewish tradition, against prefigurations of the ideal. But in more contemporary terms, this idealization, reduction and normalization are nearly impossible to avoid in a society where there are forms of expertise, expert diagnoses and expert knowledge for nearly every event and sphere of life. But is it not the case that every item of knowledge which has been established by experts is already effectively expired by the time it is applied? Does not the fixed character of such knowledge lie precisely in robbing events in the present of their open horizon, their character as real, unfolding events? A child is born, and in the judging or measuring eyes of every "wellinformed" adult, it is no longer just that "concrete child there," an absolutely new beginning in the world, a new human and a foreigner in relation to the existing order. Instead, from the perspective of such an adult, the child is integrated into a pre-existing frame of reference for normal development, of family traditions, of scientific knowledge and of everyday knowledge. That which is new is ordered according to pre-existing "knowledge-bases" and "recipes," to use the terminology of Alfred Schutz (1964), a theorist of everyday epistemologies. The child is thus made understandable and treatable. In this way, the child, before it can even attempt to engage in self-determination as an independent social actor, is already determined, and has had many of its unforeseeable possibilities eliminated. The child is already "old" before it has a chance to be young.

All of this leads to some important, general questions: Does the interrelationship of successive generations follow a measure of continuity, or is the intergenerational process principally one of discontinuity? Does not each new generation, as something radically new, have the chance to live its own life, a life that remains inescapably foreign for the parents' generation -even though it has its origins in the parents and their generation? Is it not the insuperable limit of all pedagogical action and planning, that it never really has the future at its disposal?

The French philosopher Emmanuel Lévinas (1969) developed a corresponding model of discontinuous generational procession under the rubric "fecundity." ${ }^{10}$ As Lévinas explains, the future of the son is not the future of the father. Discontinuity in the generations ensures that history does not forcibly repeat itself. Instead, it ensures that the unpredictable can happen. "My child is a stranger...but a stranger who is not only mine, for he is me. He is me a stranger to myself [sic]" (p. 267). The son continues the time of the father, which the father, as a mortal, does not himself actually have. But the son achieves this continuation in his own way, in that he 
breaks with the time of the father. In this sense, the being of the father is not an eleatic being, indivisible and unchanging in its substance. Instead, through a strange kind of intergenerational "transubstantiation," it remains open to change in its essence. The father is continued through the child. He is, through the child, an other, which continues the father's time as a future that is unavailable to him. "In existing itself there is a multiplicity and a transcendence. In this transcendence the "I" is not swept away, since the son is not me; and yet I am my son. The fecundity of the "I" is its very transcendence" (p. 277). The fecundity involved in the production of children brings about a discontinuous unity of the many. As a result, the responsibility of the parents for the future of their children suffers a radical break. How can they answer for their children if they do not also have at their disposal the time that belongs to their children? Fecundity has a particular structure: Fundamental to it is an inability that is individual, and a possibility that is dispersed, that cannot be the initiative of a single self. In this sense, children are destiny for their parents, but the destiny of a given child is not that of the parent. In a radical sense, parents cannot take any responsibility for their children, since they do not have the future of the child available to them. Should they attempt to appropriate this responsibility without a view to the difference that separates the generations, then they lose their ethical justification and grounding. In other words, in this structure, parents lose respect for the otherness of the other, which expresses itself in the generative otherness of their own children.

From the perspective of Lévinas' philosophy of the human "other," "foreignness" in pedagogy acquires a new and productive meaning. It is not merely the boundary or limit of pedagogical understanding and action, but much more. It is a discontinuity and breach between the generations which virtually holds open the relationship between children and their parents, between educators and students. Not determining, and not being able to determine that which children themselves are, opens up the actual possibility of pedagogy. It is as a result of this possibility that parents, those who are ostensibly closest to their children, are rendered foreign to themselves through their children. And children are rendered foreign in the eyes of their parents. It is only in this way that generativity and plurality is to be thought of in the context of pedagogy, which otherwise so easily shuts itself off in adult perspectives on action and meaning.

\section{Endnotes}

1 The German term for "foreign," fremd also translates as "strange." Although both possible translations for the term carry connotations important for this paper, the term is rendered here generally only as "foreign."

${ }^{2}$ Cf. the fundamental considerations regarding the theme of foreignness as presented from a phenomenological perspective (Waldenfels, 1997).

${ }^{3}$ The theme of order is also explored in Waldenfels (1996).

${ }^{4}$ See also the interpretations of Theodor Ballauff and Klaus Schaller (1970). 
${ }^{5}$ See also the concrete studies of lifeworld experience of children and of scholastic-artistic worlds of experience in Rumpf, H. (1986). or more about the model of dialectical experience as self-Bildung and its criticism, see Buck, 1984, pp. 155-230.

${ }^{6}$ For more about the model of dialectical experience as self-Bildung and its criticism, see Buck, 1984, pp. 155-230.

${ }^{7}$ For pedagogical interpretations of this aspect of Kant's theory, see also Ricken, N. (1999, p. $61)$.

${ }^{8}$ See also Lippitz, W. (2003).

${ }^{9}$ I have explained how M.J. Langeveld deals with the integral concepts of the relationship between generations in Lippitz, W. (1997).

${ }^{10}$ I have explained this in greater detail in Lippitz, W. (1989); See also, Lévinas, E. (1969). Totality and infinity: An essay on exteriority. Pittsburg: Duquesne University Press.

\section{References}

Ballauff, T., Plamböck, G. \& Schaller, K. (1969). Pädagogik: Eine Geschichte der Bildung und Erziehung. Freiburg: Alber.

Bernfeld, S. (1994).Sisyphos oder die Grenzen der Erziehung. In U. Herrmann (Ed.), Gesammelte Werke Vol. 9, Theorie und Praxis der Erziehung. Weinheim and Basel: Beltz \& Gelberg.

Bollnow,O.F. (1984). Existenzphilosophie und Pädagogik. Stuttgart: Kohlhammer.

Buck, G. (1984). Rückwege aus der Entfremdung. Studien zur Entwicklung der deutschen humanistischen Bildungsphilosophie. Paderborn: Schöningh.

Comenius, J.A. (1910). Orbis sensualium pictus. Reprint. Mannheim: Harenberg Kalender Verlag.

Elias, N. (2000). The civilizing process. London: Blackwell.

Gstettner, P. (1979). Die Eroberung des Kindes durch die Wissenschaft. Aus der Geschichte der Disziplinierung. Reinbek bei Hamburg: Rowohlt.

Kant, I. (1929). Critique of pure reason. New York: St. Martin's Press. 
Klafki, W. (2000). The significance of classical theories of bildung for a contemporary concept of allgemeinbildung. In I. Westbury, S. Hopmann, \& K. Riquarts (Eds.), Teaching as a reflective practice: The German didaktik tradition. Mahwah, NJ: Lawrence Erlbaum.

Kolleritsch, A. (1986). Lieber Sohn Julian!. In H. Haidler (Ed.), An mein Kind. Briefe von Vätern. Munich: DTV.

Langeveld, M.J. (1966). Die Schule als Weg des Kindes. 3rd Edition. Braunschweig: Georg Westerman

Lévinas, E. (1969). Totality and infinity: An essay on exteriority. Pittsburg: Duquesne University Press.

Lippitz, W. (1989). „Von Angesicht zu Angesicht" - Überlegungen zum Verhältnis von Pädagogik und Ethik im Anschluß an Levinas. Vierteljahresschrift für Wissenschaftliche Pädagogik, 65(3), 266-381.

Lippitz, W. (1997). Between "Unitary reason" and its pluralistic development. In D. Vandenberg (Ed.), Phenomenology \& educational discourse (pp. 67-100). Johannesburg: Heinemann.

Lippitz, W. (2003). Selbständige Kinder im Kontext ihrer Lebenswelt. In W. Lippitz, (Ed.), Differenz und Fremdheit (pp. 129-164). Frankfurt: Peter Lang.

Lippitz, W. \& Levering, B. (2002). "And now you are getting a teacher with such a long name...." Teaching and Teacher Education 18(2), 205-213.

Litt, T. (1965). Führen oder wachsen lassen. Stuttgart. Klett. Meyer-Drawe, K. (1999). Zum metaphorischen Gehalt von Bildung und Erziehung. Zeitschrift für Pädagogik, 45(2), 161-175.

Ricken, N. (1999). Subjektivitätund Kontingenz. Würzburg: Königshausen \& Neumann.

Rumpf, H. (1986). Mit fremdem Blick. Weinheim and Basel: Beltz \& Gelberg.

Scheibe, W. (1969). Die reformpädagogische Bewegung. Weinheim and Basel: Beltz \& Gelberg.

Schutz, A. (1964). The stranger: an essay in social psychology. In Collected papers. Vol. II. Studies in social theory. The Hague: Martinus Nijhoff.

Todorov, T. (1999).The conquest of America: The question of the other. Oklahoma City: Oklahoma UP. 
$94 \quad$ Phenomenology \& Practice

Waldenfels, B. (1996). Order in the twilight (Series in Continental Thought, No. 24). Athens, OH: Ohio University Press.

Waldenfels, B. (1997). Topographie des Fremden. Studien zur Phänomenologie des Fremden. Frankfurt am Main: Suhrkamp.

Westbury, I. (1999). Didaktik and curriculum studies. In B.B. Gundem \& S. Hopmann, (Eds.), Didaktik and/or curriculum. New York: Peter Lang. 